Research paper

\title{
Evidence of bottleneck effect on hepatitis $C$ virus transmission between a couple under interferon based therapy
}

\author{
Rafael Alves da Silva ${ }^{\mathrm{a}, \mathrm{b}}$, Isabel Maria Vicente Guedes de Carvalho ${ }^{\mathrm{b}, *}$, Renata Prandini Adum de Matos ${ }^{\mathrm{c}}$, \\ Lilian Hiromi Tomonari Yamasaki ${ }^{c}$, Cíntia Bittar ${ }^{\mathrm{c}}$, Paula Rahal ${ }^{\mathrm{c}}$, Ana Carolina Gomes Jardim ${ }^{\mathrm{c}, \mathrm{d}}$

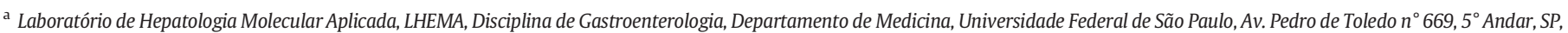 \\ Brazil \\ ${ }^{\mathrm{b}}$ Laboratório de Parasitologia, Instituto Butantan, Av. Vital Brazil, $n^{\circ} 1500$, SP, Brazil \\ ' Laboratório de Estudos Genômicos, Ibilce, UNESP, São José do Rio Preto, SP, Brazil \\ ${ }^{\mathrm{d}}$ Laboratório de Virologia, Instituto de Ciências Biomédicas, Universidade Federal de Uberlândia - UFU, Uberlândia, MG, Brazil
}

\section{A R T I C L E I N F O}

Article history:

Received 5 July 2016

Received in revised form 20 September 2016

Accepted 11 November 2016

Available online 22 November 2016

\section{Keywords:}

Hepatitis C

Bottleneck

Viral evolution

Phylogenies

Viral transmission

\begin{abstract}
A B S T R A C T
Issues on the correlation of viral genetic diversity and treatment response to the hepatitis $\mathrm{C}$ infection remain uncertain. The bottleneck effect dictates the characteristics of the viral population that will establish the infection in a new host and is related to how the immune system and treatment will be effective against the virus. Here we evaluated the phylogenetic characteristics of quasispecies population and the treatment response pattern of a $\mathrm{HCV}$ infected couple. We also analyzed whether the viral population of these patients indicated that they were exposed to the same source for primer infection. This study included two patients (P10 and P11) HCV genotype $1 \mathrm{~b}$ infected. The couple presented horizontal transmission. Viral RNA was isolated from serum samples collected before, during and after treatment, at specific time points. The HCV NS5A gene sequence was amplified, cloned and sequenced. Genetic and evolutionary analyses were performed to compare the quasispecies population of these two patients and local control patients. Genetic distance and diversity were calculated. Phylogenetic analyses were performed by using maximum likelihood and Bayesian methodologies. The analysis of the baseline samples showed that the genetic distance of the viral populations of patients P10 and P11 was significantly lower than when these patients and the control group based on sequences from local patients were analyzed, supporting the horizontal transmission hypothesis. Phylogenetic analysis with sequences from all the time point samples also demonstrated two patterns of evolution depending on the treatment response. The Bayesian analysis showed that one isolate corresponding to the baseline sample of P10 was grouped into the P11 clade, suggesting a way of infection and a bottleneck effect. Our data suggests that the patient P11 viral population may be originated from variants from P10 patient and consequently showing that clinical differences between treatment responses can emerge from the bottleneck effect on viral populations.
\end{abstract}

(c) 2016 Elsevier B.V. All rights reserved.

\section{Introduction}

The hepatitis $\mathrm{C}$ virus (HCV) is the major etiological agent related to chronic hepatitis. It is estimated that approximately 130-150 million people worldwide are currently chronically infected (WHO, 2015). The treatment of HCV infection was previously based on weekly peguilated interferon (pegINF) plus daily ribavirin (RBV) doses. This treatment induced sustained virological response (SVR) in 40\% to $50 \%$ of the patients infected with HCV genotype 1, most widely prevalent on world population (Fried et al., 2002; Manns et al., 2001). The availability of new direct-acting antivirals (DAAs) targeting the NS3

\footnotetext{
* Corresponding author.

E-mail addresses: imvgcmello@gmail.com, isabel.mello@butantan.gov.br (I.M.V.G. de Carvalho).
}

protease, NS5B polymerase and NS5A protein have improved therapeutic options (Pawlotsky, 2014). The addition of DAA's to the interferonbased therapy increased the SVR rates up to $80 \%$, for patients infected with HCV genotype 1 (Osinusi et al., 2015; Reesink et al., 2006).

The HCV is classified into genotypes 1 to 7 and 67 subtypes (Smith et al., 2014). It circulates in the infected hosts as a population of distinct but closely related viral variants denominated quasispecies. The high genetic variability is due to the high viral replication levels and to the RNA-dependent RNA polymerase that lacks a proofreading mechanism (Domingo and Gomez, 2007).

There is a positive correlation between treatment response and the HCV viral genetic diversity (Bittar et al., 2013; El-Shamy and Hotta, 2014; Jardim et al., 2009a). The high viral population complexity and the restricted availability of techniques to achieve minor viral population still make these studies hard to make (Qiu et al., 2015). 
Specific studies have investigated factors related to INF treatment resistance (Afzal et al., 2011; Pawlotsky, 2003; Zhou et al., 2011). While the resistance to DAA's treatment is caused by the described amino acid alterations related to the interaction sites between drugs and viral proteins (Alves et al., 2013; Cento et al., 2012; Lin et al., 2004), the resistance to the INF plus RBV therapy seems to be a multifactorial process that includes baseline viral population, host genotype of IL28B, immune factors, presence or absence of comorbidities as renal disease and coinfection (Angelo et al., 2013; Del Campo et al., 2013; Toyoda et al., 2011). Using techniques that are suitable to detect minor viral variants, we demonstrated previously that lower genetic diversity represents higher rates of sustained virological response. Therefore, homogeneous HCV populations are more susceptible to the immune system and INF pressures, before the IFN-based treatment (Bittar et al., 2010, 2013; Jardim et al., 2009b).

Considering that an infection event is a process associated with a bottleneck effect, the genetic diversity of the new host's viral populations are drastically decreased and can evolve according to specific genetic characteristics (Bull et al., 2011; Domingo and Holland, 1997). The way that bottleneck events can change treatments outcomes is still unanswered.

This study aimed to analyze the genetic features using phylogenetic analysis of the HCV quasispecies populations of two individuals who presented horizontal transmission and investigate if the viral population of these patients indicated that they were exposed to the same source of prior infection.

\section{Methods}

\subsection{Patients}

The patients included in this study (P10 and P11) were married, chronically HCV genotype $1 \mathrm{~b}$ infected, and presented no concomitant liver diseases [hepatitis B virus (HBV) or other hepatotropic virus infections, alcohol abuse, autoimmune hepatitis and hereditary liver diseases]. This study was approved by "The Ethics Committee of the School of Medicine of São José do Rio Preto, FAMERP". Written informed consent was obtained from both patients who consented to their individual data being included in this manuscript.

Plasma samples were collected before, during and after the end of the treatment for 48 -week, receiving PEG-IFN- $\alpha$-2b (according to body weight) subcutaneously once a week and daily RBV, taken orally at a dose of 600-1200 mg (according to body weight). Patients P10 and P11 were considered end-of-treatment responder and non-responder, respectively, as defined by the presence or absence of HCV RNA in plasma at the end of therapy and after six months.

\subsection{NS5A amplification, cloning and sequencing}

Serum samples of Patient 11 were submitted to the total RNA extraction using the commercially available QIAamp Viral RNA Kit (Qiagen, Uniscience). RNA was reverse-transcribed into cDNA using a High-Capacity cDNA Archive kit (Applied Biosystems, Foster City, CA, USA) and random primers according to the manufacturer instructions. For amplification of the entire NS5A region of the HCV genome, a nested polymerase chain reaction (PCR) was performed using the primers and reactions previously described (Jardim et al., 2009b).

PCR products of approximately $1.7 \mathrm{~kb}$ were purified and ligated into the PCR-XL-TOPO-vector using the TOPO XL PCR cloning kit (Invitrogen TM Life Technologies, Carlsbad, CA, USA). The ligation products were transformed into competent cells (Invitrogen TM Life Technologies, Carlsbad, CA, USA). Fifteen transformants were randomly chosen for further analysis, and DNA plasmids were isolated from a 3.0-ml broth culture using the GeneJET plasmid Miniprep Kit (Fermentas). Recombinant PCR-XL-TOPO-NS5A clones were sequenced using dideoxy terminator automated sequencing (ABI Prism Ready Reaction Mix; Applied
Biosystems, Foster City, CA, USA) using an ABI Prism 377 and ABI 3130XL sequencers, according to the manufacturer's instructions (Applied Biosystems Inc., Foster City, CA, USA.). Eight to ten sequencing reactions were performed for each clone as previously described (Jardim et al., 2009b).

\subsection{Genetic and phylogenetic analysis}

Nucleotides sequences corresponding to the HCV strains of P10 and patients of the control group (P05, P42 and P44) were obtained from GenBank (accession number EU309511-EU309525, EU309586EU309599, EU309600-EU309614, HQ823765-HQ824349). These sequences were generated by our research group and analyzed in a previous study (Jardim et al., 2009b, 2013). Patient's characteristics are represented on Supplementary Table 1.

Sequences from this work were analyzed for chromatograms quality using Phred-Phrap algorithm (de la Bastide and McCombie, 2007; Ewing and Green, 1998; Lee and Vega, 2004; Machado et al., 2011). All contigs were aligned using ClustalX 2.0 (Larkin et al., 2007).

Genetic distance was evaluated by the number of base substitutions per site from estimation of net average between groups of sequences using the Maximum Composite Likelihood model using JModeltest parameters and MEGA 6.0 software. The analysis involved 75 nucleotide sequences (15 sequences for each baseline sample).

To investigate the genetic relationship among HCV quasispecies of P10, P11 and the local patients, phylogenetic reconstructions were performed with all NS5A sequences corresponding to samples of P10, P11 and controls patients. The Maximum Likelihood trees were reconstructed using GTR + G + I evolutionary model (General Time Reversible plus gamma variation and Invariant sites) as placed by JModeltest (Darriba et al., 2012; Tamura et al., 2013; Waddell and Steel, 1997). A thousand replicates were used to test the support given by the data to the clusters of the tree topology with Bootstrap resampling technique (Brown, 1994).

After data inferred strong relationship between P10 and P11 quasispecies, further phylogenetic reconstructions were performed using maximum likelihood and Bayesian algorithms in MEGA 6.0 and MrBayes3.2 (Ronquist et al., 2012; Tamura et al., 2013) respectively. Bootstrap pseudo-replicates and posterior probabilities were used to support clades.

\section{Results}

\subsection{HCV variants from P10 and P11 are more closely related}

Phylogenetic analysis was first performed using sequences corresponding to before, during and after treatment samples of P10, P11 and three non-related patients of control group (P04, P42 and P44). This data was assessed in order to evaluate the degree of genetic relationship among those variants by analyzing clades patterns. HCV variants from P10 and P11 grouped in a monophyletic cluster separated from the cluster with variants from the control group, showing that they are more closely related than with isolates from other patients (bootstrap values $=100$ ). Sequences from P10 and P11 presented a more recent common ancestor than control group based on the lower genetic distance observed by branch length separation for its clades (Fig. 1).

The closer relationship among variants from P10 and P11 could suggest either hypothesis: they were exposed to the same source of contamination or one was previously infected and transmitted the virus to their partner. To further investigate these assumptions, genetic distance among isolates from baseline sample of P10, P11 and control group patients was further investigated. The results demonstrated that lower genetic distance was observed between P10 and P11 variants $(0,030$ SD 0,004$)$ than between their variants and the isolates of control patients (e.g. P44 an P10 $=0.078$ SD 0.009) (Fig. 2). 
A.

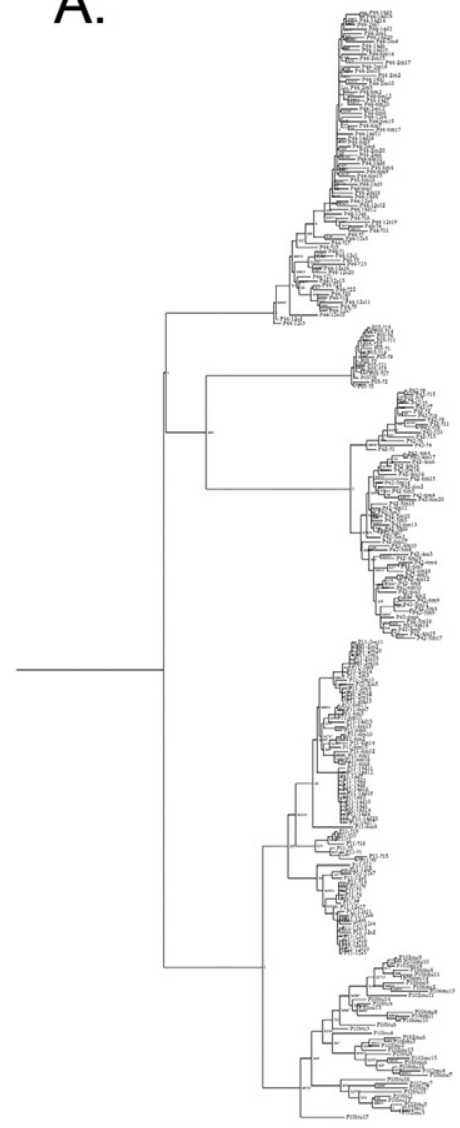

B.

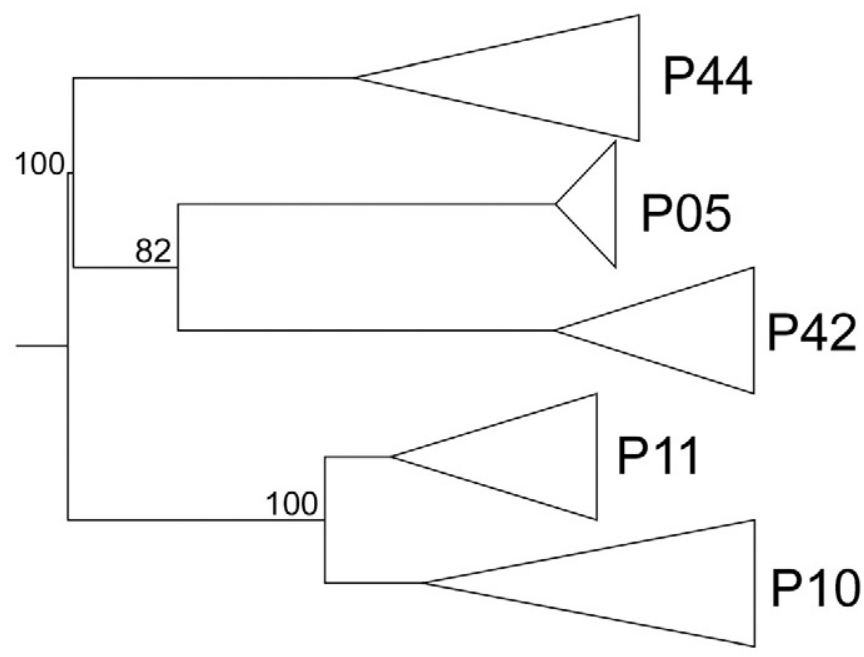

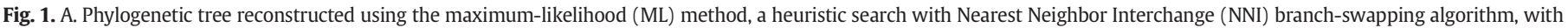

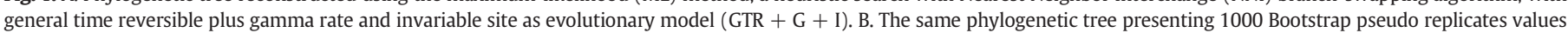
represented on the branches and sequences collapsed for better visualization.

\subsection{The isolate P10btc17 is as an out group for P10 and P11}

Next, the impact of interferon and ribavirin on viral populations of patients 10 and 11 was analyzed. Genetic distance calculations determined the impact of therapy on viral populations by using nucleotide substitutions between before and after treatment variants. The results demonstrated different profiles of genetic distance over time for P10 and P11 quasispecies. Isolates of baseline and post-treatment from P10, an ETR patient, demonstrated lower genetic distance (b vs $2 \mathrm{~m}=0.002$; b vs $6 \mathrm{~m}=0.005$ ) than from P11 variants, a NR patient (b vs $2 \mathrm{~m}=0.016$; b vs $6 \mathrm{~m}=0.022$ ) (Fig. 3 ).
The phylogenetic reconstruction (ML and Bayesian) clearly showed two different clades for patient P11 variants, sustained by a bootstrap value higher than 90 , one with variants from baseline and 12 weeks of treatment samples and another with post-treatment isolates (Fig. 4). Additionally, P11 viral load was higher than $4.0 \mathrm{log} \mathrm{UI} / \mathrm{ml}$ all over time including the sample collected at 12 weeks of treatment. This profile for NR patients raises questions about the genetic characteristics of the resistant population. In contrast, variants isolated from baseline and post-treatment samples of P10 grouped together showing a higher homogeneity (Fig. 4). This patient viral load was undetected by the end of the treatment, recovering to detectable levels two months after. The
A.

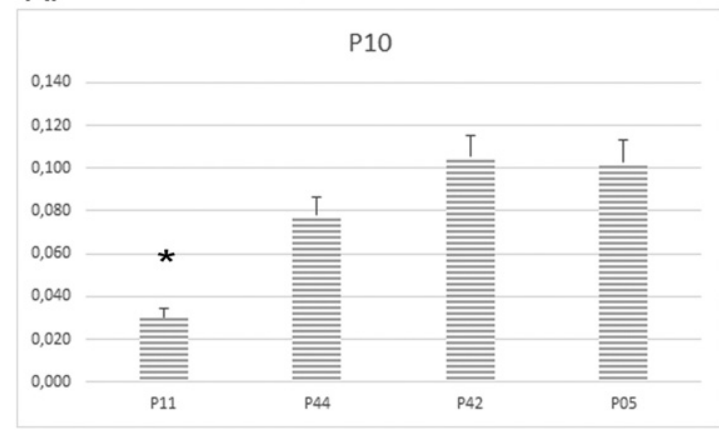

B.

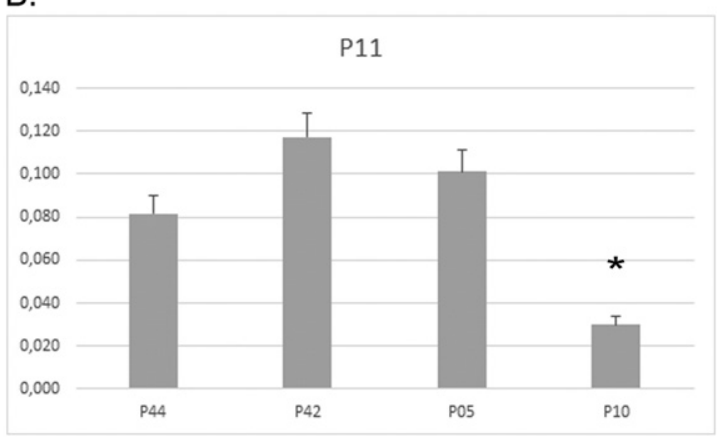

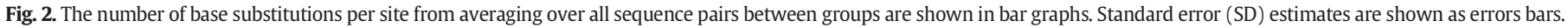

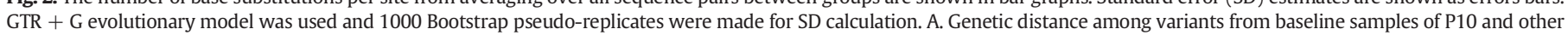
local patients. B. Genetic distance among variants from baseline samples of P11 and control local patients. 


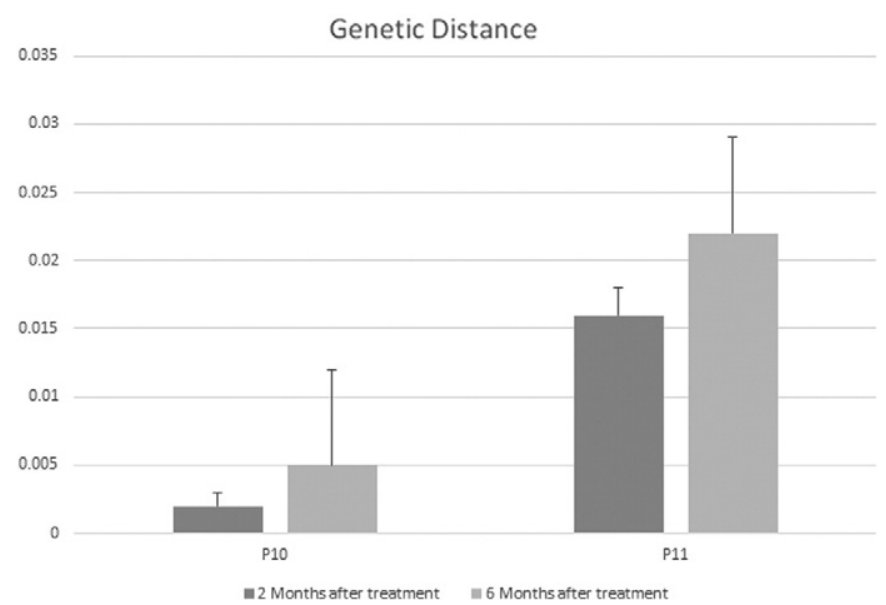

Fig. 3. Genetic distance among quasispecies from baseline and post-treatment samples ( 2 months and 6 months) of P10 and P11. The number of base substitutions per site from averaging over all sequence pairs between groups is shown in bar graphs. The evolutionary model GTR $+\mathrm{G}$ was used as indicate by JModeltest 2.0.

differentiation of ancestral clades among different samples was not significantly sustained by bootstrap and clades did not presented a unique pattern.

Despite the similar evolutionary pattern, MCMC phylogenetic reconstruction (Fig. 4B) showed that one sequence from patient P10 presented a higher genetic similarity with P11 patient. Using a variable molecular clock already optimized for HCV, the MCMC tree showed that the sequence P10btc17 was grouped with P11 patient sequences (Fig. 4B). On ML phylogenetic method, the isolated P10btc17 was presented in the reconstructed tree as an ancestral out group sequence of P10 clade (Fig. 4A). This fact, associated with the ancestral branch length in P10 clades, suggests a way of infection going from patient 10 to patient 11 .

\section{Discussion}

The genetic diversity of HCV population is high even when a single infected patient is considered. The concept of quasispecies is applied to better understand the complexity of viral populations and its impact on both virus evolution and resistance to the current treatments (Domingo and Gomez, 2007). Considering that point mutations into the NS5A region of HCV have not been related to resistance to the interferon based therapy, the interference of viral genetic diversity of this region on $\mathrm{HCV}$ infection must be considered.

The baseline HCV genetic diversity has been related to treatment response. Genetic heterogeneity seems to be an advantage for HCV to escape from treatment and host selective pressures (El-Shamy et al., 2011; Jardim et al., 2013). Our group previously evaluated viral isolates from genotype $1 \mathrm{HCV}$ infected patients and demonstrated that genetic heterogeneity of viral populations at baseline samples may influence on treatment outcome (Jardim et al., 2013). However, issues on the diversity and heterogeneity of viral populations under selective pressure of interferon-based treatment are still unclear.

Despite the correlation between genetic diversity and treatment response, several questions about the genetic complexity of HCV populations, immunologic response, treatment outcome and quasispecies evolution still have to be answered. Bottleneck events have a major role in determining the evolution of host's new viral population, and specific genetic characteristic's to cause escapes of treatments and immunological pressures.

Here we investigated the genetic and phylogenetic features of the HCV populations of two individuals who presented horizontal transmission risks. Patients P10 and P11 responded differentially to the PEG-IFN and ribavirin therapy despite of either a possible common source of contamination or the virus transmission from each other.

The divergence of viral populations during and after therapy pressure is an important factor that can influence the treatment outcome. How virus mutates determines the immune system recognition of specific epitopes and the therapy outcome (Petrovic et al., 2012; Timm and Walker, 2015). As an ETR patient, P10 demonstrated undetectable levels of viral load by the end of the treatment, but the response was not sustained later. The continuous heterogeneity of viral populations at baseline and after treatment for P10 observed by the closer phylogenetic relation of variants infers that the decrease of viral load during the treatment did not interfere in the viral population diversity. There are some hypotheses for this finding. As observed in our previous data, the viral load decrease was not enough for viral clearance and the variants that remained were able to recover population diversity similar to the levels observed at baseline. Alternatively, a resistant variant that rose by mutation, was able to escape the treatment and diversify the genetic population two months after the end of treatment (Bittar et al., 2013; Jardim et al., 2013). For P11, a non-responder, the treatment only reduced the viral load. The clade's profile among variants across the time may suggest that the virus needed to adapt its genetic information as an alternative to overcome the pressure of treatment. The constant genetic modifications were observed by the clear separation of clades and the higher genetic diversity between before and after treatment sequences.

By performing genetic distance and phylogenetic analyses, our data demonstrated that HCV variants from P10 and P11 are more closely related than with isolates from other local patients. The evidence of a closer genetic relationship among variants of these patients could suggest either hypothesis: they were exposed to the same source of contamination or one was previously infected and transmitted the virus to their partner.

Additionally, the sequence P10btc17 presented as an out group for P10 isolates on ML analysis and for P11 variants on Bayesian analysis suggested a way of infection going from P10 to P11. This data is reinforced by the higher sensibility of the Bayesian algorithm and priors used to analyze genetic viral characteristics. The presence of one single population in a clade origin position can indicate that the hypothesis of horizontal transmission is more reliable than same source infection.

Sexual transmission of HCV is a contradictory issue. Since the HCV identification in 1989, prospective studies have been inconclusive and have lacked the consensus of data (de Carvalho-Mello et al., 2010; Tahan et al., 2005; Vandelli et al., 2004). In addition, the household risks by sharing razors or other personal hygiene materials for example can be an even more effective source of HCV infection than sexual transmission. The hypothesis of the HCV transmission from P10 to P11 is supported by the closer genetic distance between these patients' quasispecies as well as the presence of the out group P10btc17 sequence on the major clade of sequences from P11. Patients from this study consented to fill forms concerning the risk factors for the HCV acquisition and stated to experience some conditions considered as a risk such as surgeries, medical and dental procedures, unprotected sexual relations, razor sharing etc. Particularly, patient 10 has declared to have performed an induced abortion and curettage with a midwife in 1963. Another occurrence was an acupuncture treatment using collective needles. Both patients also declared to maintain sexual relationship after the HCV positive diagnosis. Acupuncture needles have already demonstrated to carry HCV (Lemos et al., 2014) and the abortion procedure before the identification of HCV could also suggest a strong source of infection to P10 with posterior transmission to P11. However, the influence of this data on HCV acquisition and transmission between P10 and 11 could not be clearly addressed.

The phylogenetic position of the sequence associated to the P11 infection origin (P10btc17) demonstrates no clear genetic similarity to the post treatment sequences from P10, in both analyses. Considering the NR patient profile, the hypothesis that the HCV population with 

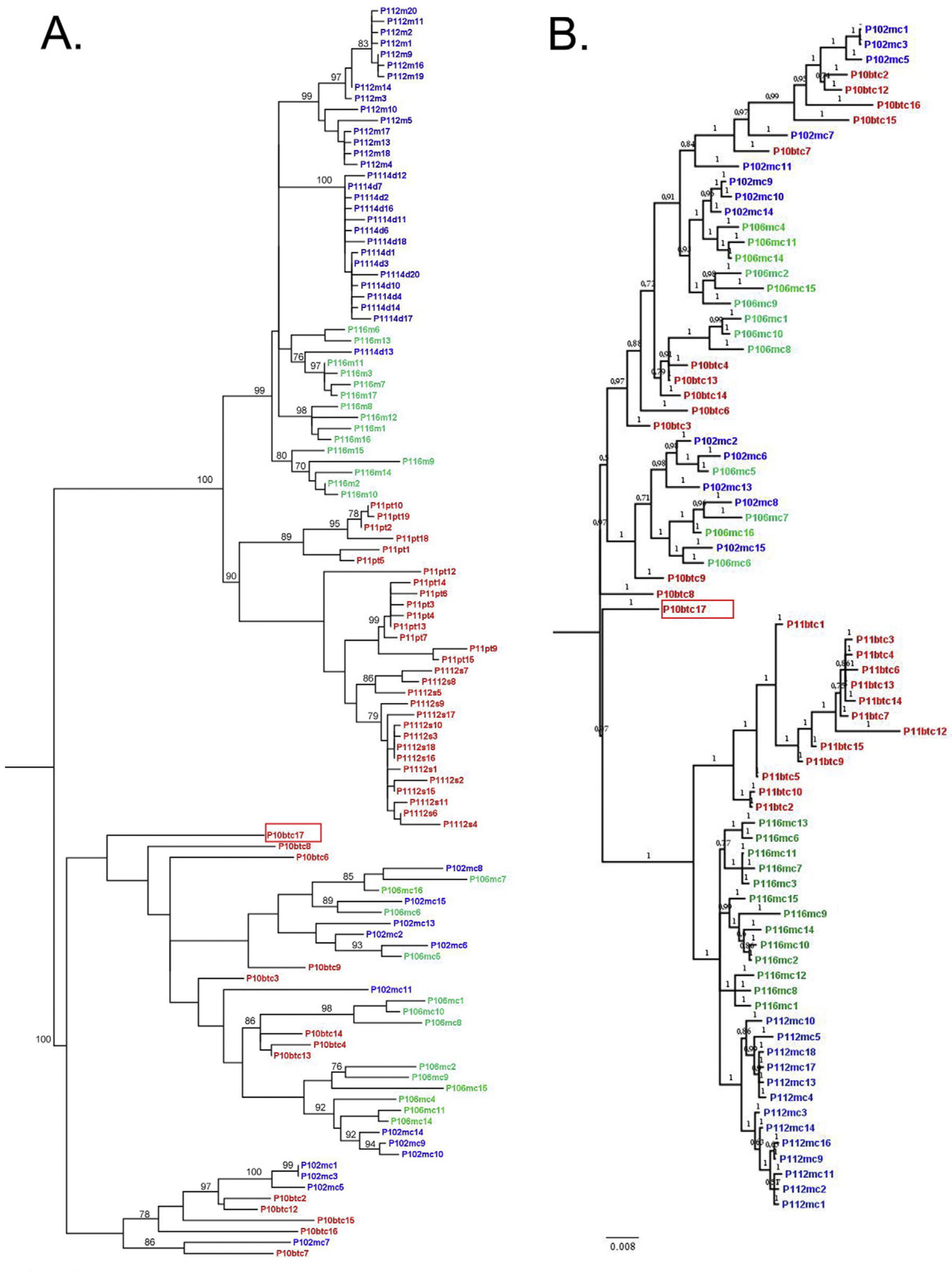

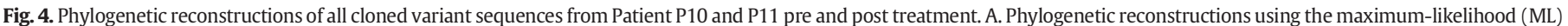

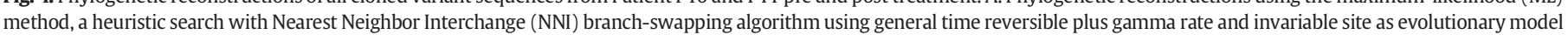

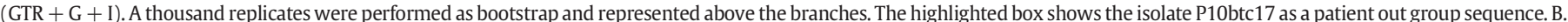

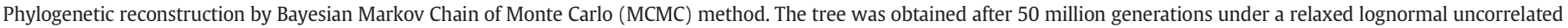

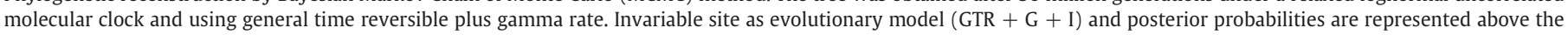
branches. Convergence values obtained were $>200$. The highlighted box shows the isolate P10btc17 as a patient P11 out group sequence. 
treatment resistance on P10 patient was the population transmitted thought a bottleneck effect can be corroborated by the closer genetic relationship in both phylogenetic analyses.

The transmission of the HCV population between patients could be contested by differences observed in the treatment response presented by each one after the selective pressure imposed by the same PEG/RBV treatment regimen. Factors as the host's immune genetic characteristics could be the cause of the different treatment outcomes, but, considering the importance of the genetic diversity the bottleneck effect can be at least partially responsible for that difference. Despite published data already supporting spouse-to-spouse transmission, (Caraballo Cortes et al., 2016; Njouom et al., 2011; Tahan et al., 2005) our work is the first to report the transmission of a HCV population from two patients with different treatment responses and phylogenetic evidence of a bottleneck event.

\section{Conclusion}

Our data suggests that the P11 viral population may be originated from variants from P10 patient. In the new host (P11) these isolates were not able to restore a population as diverse as the one observed at the source of contamination, but was efficient to escape from the immune system and IFN-based therapy pressures.

Supplementary data to this article can be found online at http://dx. doi.org/10.1016/j.meegid.2016.11.012.

\section{Financial support}

This work was supported by grants from FAPESP (Fundação de Amparo a Pesquisa do Estado de São Paulo) under the project numbers 2007/52073-0, 2008/51165-1, 2010/06156-4 and 2012/18168-2.

\section{Acknowledgments}

We acknowledge Fernando Kamitani, Ph.D. from Laboratório de Parasitologia of Butantan Institute for grammar review.

\section{References}

Afzal, S., Idrees, M., Ali, M., Ilyas, M., Hussain, A., Akram, M., Butt, S., Saleem, S., Rehman, I.U., Ali, L., Shahid, M., 2011. Envelope 2 protein phosphorylation sites S75 \& 277 of hepatitis $C$ virus genotype $1 \mathrm{a}$ and interferon resistance: a sequence alignment approach. Virol. J. 8:71. http://dx.doi.org/10.1186/1743-422X-8-71.

Alves, R., Queiroz, A.T.L., Pessoa, M.G., da Silva, E.F., Mazo, D.F.C., Carrilho, F.J., CarvalhoFilho, R.J. de Carvalho, I.M.V.G., 2013. The presence of resistance mutations to protease and polymerase inhibitors in hepatitis $C$ virus sequences from the Los Alamos databank. J. Viral Hepat. http://dx.doi.org/10.1111/jvh.12051 (n/a-n/a).

Angelo, A.L.D., Cavalcante, L.N., Abe-Sandes, K., Machado, T.B., Lemaire, D.C., Malta, F. Pinho, J.R., Lyra, L.G.C., Lyra, A.C., 2013. Myxovirus resistance, osteopontin and suppressor of cytokine signaling 3 polymorphisms predict hepatitis $C$ virus therapy response in an admixed patient population: comparison with IL28B. Clinics (Sao Paulo) 68:1325-1332. http://dx.doi.org/10.6061/clinics/2013(10)06.

Bittar, C., Jardim, A.C.G., Yamasaki, L.H.T., de Queiróz, A.T.L., Carareto, C.M.A., Pinho, J.R.R., de Carvalho-Mello, I.M.V.G., Rahal, P., 2010. Genetic diversity of NS5A protein from hepatitis $C$ virus genotype $3 \mathrm{a}$ and its relationship to therapy response. BMC Infect. Dis. 10:36. http://dx.doi.org/10.1186/1471-2334-10-36.

Bittar, C., Jardim, A.C.G., Yamasaki, L.H.T., Carareto, C.M.A., Pinho, J.R.R., Lemey, P., de Carvalho-Mello, I.M.V.G., Rahal, P., 2013. On hepatitis C virus evolution: the interaction between virus and host towards treatment outcome. PLoS One 8, e62393. http://dx.doi.org/10.1371/journal.pone.0062393.

Brown, J.K., 1994. Bootstrap hypothesis tests for evolutionary trees and other dendrograms. Proc. Natl. Acad. Sci. U. S. A. 91, 12293-12297.

Bull, R.A., Luciani, F., McElroy, K., Gaudieri, S., Pham, S.T., Chopra, A., Cameron, B., Maher, L., Dore, G.J., White, P.A., Lloyd, A.R., 2011. Sequential bottlenecks drive viral evolution in early acute hepatitis C virus infection. PLoS Pathog. 7, e1002243. http://dx.doi.org/10. 1371/journal.ppat.1002243.

Caraballo Cortes, K., Zagordi, O., Jabłońska, J., Pawełczyk, A., Kubisa, N., Perlejewski, K., Bukowska-Ośko, I., Płoski, R., Radkowski, M., Laskus, T., 2016. Spouse-to-spouse transmission and evolution of hypervariable region 1 and $5^{\prime}$ untranslated region of hepatitis $\mathrm{C}$ virus analyzed by next-generation sequencing. PLoS One 11, e0150311. http://dx.doi.org/10.1371/journal.pone.0150311.

Cento, V., Mirabelli, C., Salpini, R., Dimonte, S., Artese, A., Costa, G., Mercurio, F., Svicher, V., Parrotta, L., Bertoli, A., Ciotti, M., Di Paolo, D., Sarrecchia, C., Andreoni, M., Alcaro, S., Angelico, M., Perno, C.F., Ceccherini-Silberstein, F., 2012. HCV genotypes are differently prone to the development of resistance to linear and macrocyclic protease inhibitors. PLoS One 7, e39652. http://dx.doi.org/10.1371/journal.pone.0039652.

Darriba, D., Taboada, G.L., Doallo, R., Posada, D., 2012. jModelTest 2: more models, new heuristics and parallel computing. Nat. Methods 9:772. http://dx.doi.org/10.1038/nmeth.2109.

de Carvalho-Mello, I.M.V.G., Filho, J.E.M., Gomes-Gouvêa, M.S., de Mello Malta, F., de Queiróz, A.T.L., Pinho, J.R.R., Carrilho, F.J., 2010. Molecular evidence of horizontal transmission of hepatitis C virus within couples. J. Gen. Virol. 91:691-696. http:// dx.doi.org/10.1099/vir.0.015594-0.

de la Bastide, M., McCombie, W.R., 2007. Assembling genomic DNA sequences with PHRAP. Curr. Protoc. Bioinformatics http://dx.doi.org/10.1002/0471250953. bi1104s17 (Chapter 11, Unit11.4).

Del Campo, J.a., Ampuero, J., Rojas, L., Conde, M., Rojas, A., Maraver, M., Millán, R., GarcíaValdecasas, M., García-Lozano, J.R., González-Escribano, M.F., Romero-Gómez, M., Rojas, Á., Maraver, M., Millán, R., García-Valdecasas, M., García-Lozano, J.R., González-Escribano, M.F., Romero-Gómez, M., 2013. Insulin resistance predicts sustained virological response to treatment of chronic hepatitis $C$ independently of the IL28b rs12979860 polymorphism. Aliment. Pharmacol. Ther. 37:74-80. http:// dx.doi.org/10.1111/apt.12113.

Domingo, E., Gomez, J., 2007. Quasispecies and its impact on viral hepatitis. Virus Res. 127:131-150. http://dx.doi.org/10.1016/j.virusres.2007.02.001.

Domingo, E., Holland, J.J., 1997. RNA virus mutations and fitness for survival. Annu. Rev Microbiol. 51:151-178. http://dx.doi.org/10.1146/annurev.micro.51.1.151.

El-Shamy, A., Hotta, H., 2014. Impact of hepatitis C virus heterogeneity on interferon sensitivity: an overview. World J. Gastroenterol. 20:7555-7569. http://dx.doi.org/10. 3748/wjg.v20.i24.7555.

El-Shamy, A., Shoji, I., Saito, T., Watanabe, H., Ide, Y.-H., Deng, L., Kawata, S., Hotta, H., 2011. Sequence heterogeneity of NS5A and core proteins of hepatitis C virus and virological responses to pegylated-interferon/ribavirin combination therapy. Microbiol. Immunol. 55:418-426. http://dx.doi.org/10.1111/j.1348-0421.2011.00331.x.

Ewing, B., Green, P., 1998. Base-calling of automated sequencer traces using phred. II Error probabilities. Genome Res. 8:186-194. http://dx.doi.org/10.1101/gr.8.3.186.

Fried, M.W., Shiffman, M.L., Reddy, K.R., Smith, C., Marinos, G., Gonçales, F.L., Häussinger D., Diago, M., Carosi, G., Dhumeaux, D., Craxi, A., Lin, A., Hoffman, J., Yu, J., 2002. Peginterferon alfa-2a plus ribavirin for chronic hepatitis C virus infection. N. Engl. J. Med. Mass Med. Soc.

Jardim, A.C.G., Yamasaki, L.H.T., de Queiróz, A.T.L., Bittar, C., Pinho, J.R.R., Carareto, C.M.A. Rahal, P., de C. Mello, I.M.V.G., 2009a. Quasispecies of hepatitis C virus genotype 1 and treatment outcome with peginterferon and ribavirin. Infect. Genet. Evol. 9:689-698. http://dx.doi.org/10.1016/j.meegid.2008.11.001.

Jardim, A.C.G., Yamasaki, L.H.T., de Queiróz, A.T.L., Bittar, C., Pinho, J.R.R., Carareto, C.M.A Rahal, P., Mello, I.M.V.G.D.C., 2009b. Quasispecies of hepatitis C virus genotype 1 and treatment outcome with peginterferon and ribavirin. Infect. Genet. Evol. 9:689-698. http://dx.doi.org/10.1016/j.meegid.2008.11.001.

Jardim, A.C., Bittar, C., Matos, R.P., Yamasaki, L.H., Silva, R.A., Pinho, J.R., Fachini, R.M., Carareto, C.M., de Carvalho-Mello, I.M., Rahal, P., 2013. Analysis of HCV quasispecies dynamic under selective pressure of combined therapy. BMC Infect. Dis. 13:61. http://dx.doi.org/10.1186/1471-2334-13-61.

Larkin, M.A., Blackshields, G., Brown, N.P., Chenna, R., McGettigan, P.A., McWilliam, H. Valentin, F., Wallace, I.M., Wilm, A., Lopez, R., Thompson, J.D., Gibson, T.J., Higgins, D.G., 2007. Clustal W and Clustal X version 2.0. Bioinformatics 23, 2947-2948 (doi: btm404 [pii]10.1093/bioinformatics/btm404).

Lee, W.H., Vega, V.B., 2004. Heterogeneity detector: finding heterogeneous positions in Phred/Phrap assemblies. Bioinformatics 20:2863-2864. http://dx.doi.org/10.1093/ bioinformatics/bth301.

Lemos, M.A., Silva, J.B.G., Braga, A.C.S., Carneiro, B.M., Rahal, P., Silva, R.C.M.A., 2014. Acupuncture needles can carry hepatitis C virus. Infect. Control Hosp. Epidemiol. 35 1319-1321. http://dx.doi.org/10.1086/678079.

Lin, C., Lin, K., Luong, Y.-P., Rao, B.G., Wei, Y.-Y., Brennan, D.L., Fulghum, J.R., Hsiao, H.-M., Ma, S., Maxwell, J.P., Cottrell, K.M., Perni, R.B., Gates, C.a., Kwong, A.D., 2004. In vitro resistance studies of hepatitis $C$ virus serine protease inhibitors, VX-950 and BILN 2061: structural analysis indicates different resistance mechanisms. J. Biol. Chem. 279:17508-17514. http://dx.doi.org/10.1074/jbc.M313020200.

Machado, M., Magalhães, W.C., Sene, A., Araújo, B., Faria-Campos, A.C., Chanock, S.J., Scott, L., Oliveira, G., Tarazona-Santos, E., Rodrigues, M.R., 2011. Phred-Phrap package to analyses tools: a pipeline to facilitate population genetics re-sequencing studies. Investig. Genet. 2:3. http://dx.doi.org/10.1186/2041-2223-2-3.

Manns, M.P., McHutchison, J.G., Gordon, S.C., Rustgi, V.K., Shiffman, M., Reindollar, R. Goodman, Z.D., Koury, K., Ling, M., Albrecht, J.K., 2001. Peginterferon alfa-2b plus ribavirin compared with interferon alfa-2b plus ribavirin for initial treatment of chronic hepatitis C: a randomised trial. Lancet.

Njouom, R., Lavoie, M., Foupouapouognigni, Y., Frost, E., Deslandes, S. Mamadou-Yaya, F. Mbélesso, P., Mbadingai, S., Pépin, J., 2011. Transmission of hepatitis C virus among spouses in Cameroon and the Central African Republic. J. Med. Virol. 83:2113-2118. http://dx.doi.org/10.1002/jmv.22225.

Osinusi, A., Townsend, K., Kohli, A., Nelson, A., Seamon, C., Meissner, E.G., Bon, D., Silk, R. Gross, C., Price, A., Sajadi, M., Sidharthan, S., Sims, Z., Herrmann, E., Hogan, J., Teferi, G. Talwani, R., Proschan, M., Jenkins, V., Kleiner, D.E., Wood, B.J., Subramanian, G.M., Pang, P.S., McHutchison, J.G., Polis, M.a., Fauci, A.S., Masur, H., Kottilil, S., 2015. Virologic response following combined ledipasvir and sofosbuvir administration in patients with HCV genotype 1 and HIV co-infection. JAMA 313:1232-1239. http://dx doi.org/10.1001/jama.2015.1373.

Pawlotsky, J.-M., 2003. The nature of interferon-alpha resistance in hepatitis C virus infection. Curr. Opin. Infect. Dis. 16:587-592. http://dx.doi.org/10.1097/01.qco.0000104300. 87920.03 .

Pawlotsky, J.M., 2014. New hepatitis C therapies: the toolbox, strategies, and challenges. Gastroenterology 146:1176-1192. http://dx.doi.org/10.1053/j.gastro.2014.03.003. 
Petrovic, D., Dempsey, E., Doherty, D.G., Kelleher, D., Long, A., 2012. Hepatitis C virus - Tcell responses and viral escape mutations. Eur. J. Immunol. 42:17-26. http://dx.doi. org/10.1002/eji.201141593.

Qiu, P., Stevens, R., Wei, B., Lahser, F., Howe, A.Y.M., Klappenbach, J.A., Marton, M.J., 2015. HCV genotyping from NGS short reads and its application in genotype detection from HCV mixed infected plasma. PLoS One 10, e0122082. http://dx.doi.org/10.1371/ journal.pone.0122082.

Reesink, HW, Zeuzem, S, Weegink, CJ. Forestier, N, Van Vliet, A, Van De Wetering De Rooij, J., McNair, L., Purdy, S., Kauffman, R., Alam, J., Jansen, P.L.M., 2006. Rapid decline of viral RNA in hepatitis C patients treated with VX-950: a phase Ib, placebo-controlled, randomized study. Gastroenterology.

Ronquist, F., Teslenko, M., van der Mark, P., Ayres, D.L., Darling, A., Höhna, S., Larget, B., Liu, L., Suchard, M.A., Huelsenbeck, J.P., 2012. MrBayes 3.2: efficient Bayesian phylogenetic inference and model choice across a large model space. Syst. Biol. 61:539-542. http://dx.doi.org/10.1093/sysbio/sys029.

Smith, D.B., Bukh, J., Kuiken, C., Muerhoff, A.S., Rice, C.M., Stapleton, J.T., Simmonds, P., 2014. Expanded classification of hepatitis $C$ virus into 7 genotypes and 67 subtypes: updated criteria and genotype assignment web resource. Hepatology 59:318-327. http://dx.doi.org/10.1002/hep.26744.

Tahan, V., Karaca, C., Yildirim, B., Bozbas, A., Ozaras, R., Demir, K., Avsar, E., Mert, A. Besisik, F., Kaymakoglu, S., Senturk, H., Cakaloglu, Y., Kalayci, C., Okten, A., Tozun, N., 2005. Sexual transmission of HCV between spouses. Am. J. Gastroenterol. 100: 821-824. http://dx.doi.org/10.1111/j.1572-0241.2005.40879.x.

Tamura, K., Stecher, G., Peterson, D., Filipski, A., Kumar, S., 2013. MEGA6: molecular evolutionary genetics analysis version 6.0. Mol. Biol. Evol. 30:2725-2729. http://dx.doi. org/10.1093/molbev/mst197.
Timm, J., Walker, C.M., 2015. Mutational escape of CD8 + T cell epitopes: implications for prevention and therapy of persistent hepatitis virus infections. Med. Microbiol. Immunol. 204:29-38. http://dx.doi.org/10.1007/s00430-014-0372-z.

Toyoda, H., Kumada, T., Tada, T., Kawaguchi, T., Murakami, Y., Matsuda, F., 2011. Impact of genetic polymorphisms near the IL28B gene and amino acid substitutions in the hepatitis $C$ virus core region on interferon sensitivity/resistance in patients with chronic hepatitis C. J. Med. Virol. 83:1203-1211. http://dx.doi.org/10.1002/jmv.22092.

Vandelli, C. Renzo, F, Romanò, L Tisminetzky, S, De Palma, M., Stroffolini, T., Ventura, E., Zanetti, A., 2004. Lack of evidence of sexual transmission of hepatitis C among monogamous couples: results of a 10-year prospective follow-up study. Am. J. Gastroenterol. 99:855-859. http://dx.doi.org/10.1111/j.1572-0241.2004.04150.x.

Waddell, P.J., Steel, M.A., 1997. General time-reversible distances with unequal rates across sites: mixing gamma and inverse Gaussian distributions with invariant sites. Mol. Phylogenet. Evol. 8:398-414. http://dx.doi.org/10.1006/mpev.1997.0452.

Zhou, X.-M., Chan, P.K. Tam, J.S., 2011. Mutations around interferon sensitivity-determining region: a pilot resistance report of hepatitis $C$ virus $1 \mathrm{~b}$ in a Hong Kong population. World J. Gastroenterol. 17:5317-5323. http://dx.doi.org/10.3748/wjg.v17.i48.5317.

\section{Online reference}

WHO, 2015. http://www.who.int/mediacentre/factsheets/fs164/en/ (Accessed 09/03/ 2016). 